\title{
Stabilization of nickel nanoparticle suspensions with the aid of polymer and surfactant: static bottle tests and dynamic micromodel flow tests
}

\author{
Siyuan $\mathrm{Yi}^{1} \cdot$ Tayfun Babadagli $^{1} \cdot$ Huazhou $\mathrm{Li}^{1}$
}

Received: 17 July 2019 / Published online: 27 February 2020

(c) The Author(s) 2020

\begin{abstract}
Nickel nanoparticles can work as catalyst for the aquathermolysis reactions between water and heavy oil. A homogeneous and stable suspension is needed to carry the nickel nanoparticles into deeper reservoirs. This study conducts a detailed investigation on how to achieve stabilized nickel nanoparticle suspensions with the use of surfactant and polymer. To stabilize the nickel nanoparticle suspension, three surfactants including sodium dodecyl sulfate, cationic surfactant cetyltrimethylammonium bromide and polyoxyalkalene amine derivative (Hypermer) along with xanthan gum polymer were introduced into the nickel nanoparticle suspension. Static stability tests and zeta potential measurements were conducted to determine the polymer/surfactant recipes yielding the most stable nickel nanoparticle suspensions. Dynamic micromodel flow tests were also conducted on three suspensions to reveal how the nickel nanoparticles would travel and distribute in porous media. Test results showed that when the injection was initiated, most nickel nanoparticles were able to pass through the gaps between the sand grains and produced in the outlet of the micromodel; only a small number of the nickel nanoparticles were attached to the grain surface. A higher nickel concentration in the suspension may lead to agglomeration of nickel nanoparticles in porous media, while a lower concentration can mitigate this agglomeration. Moreover, clusters tended to form when the nickel nanoparticle suspension carried an electrical charge opposite to that of the porous media. Follow-up waterflood was initiated after the nanofluid injection. It was found that the waterflood could not flush away the nanoparticles that were remaining in the micromodel.
\end{abstract}

Keywords Aquathermolysis reactions $\cdot$ Nickel nanoparticles $\cdot$ Polymer surfactant $\cdot$ Suspension stability

\section{Introduction}

Nanotechnology holds a big potential for finding many successful applications in the petroleum industry. It has been reported by Kong and Ohadi (2010) that nanotechnology is capable of bringing revolutionary changes in the fields of oil exploration, drilling, production, enhanced oil recovery (EOR), etc. For example, a more detailed and accurate information about the reservoir can be provided with the employment of nanosensors in the reservoir, and the use of

Edited by Yan-Hua Sun

Huazhou Li

huazhou@ualberta.ca

1 School of Mining and Petroleum Engineering, Faculty of Engineering, University of Alberta, Edmonton T6G 1H9, Canada nanomembranes can help to effectively remove impurities from oil and gas streams (Kong and Ohadi 2010).

Moreover, the oil recovery could be improved by injecting nanoparticles into the porous media along with the in situ upgrading of heavy oil and bitumen. It has been reported by Clark et al. (1990) that transition metal species can act as catalyst for aquathermolysis reactions (chemical reactions between oil and steam which release hydrocarbon gases, hydrogen sulfide, carbon dioxide and hydrogen and further reduce the heavy oil viscosity), in situ upgrading heavy oil. Later on, many researchers started to study the catalytic effect that metal species have on the aquathermolysis reactions. The experiments conducted by Wei et al. (2007) indicated that the aquathermolysis reaction with the use of nickel nanoparticles yielded lower-viscosity heavy oil with a lower mean molecular weight. By conducting experiments with trimetallic nanocatalysts, enhanced oil recovery was obtained by Hashemi et al. (2013). Ragab and Hannora 
(2015) injected silica nanofluid into a sandstone core and found that the finer the nanoparticle was, the higher the oil recovery could be achieved. Built upon these previous research achievements, Yi et al. (2017) conducted an experimental study of the use of nickel nanoparticles for promoting aquathermolysis reactions during cyclic steam stimulation; under the experimental conditions, the optimum nickel nanoparticle concentration was found to be $0.200 \mathrm{wt} \%$. But it should be noted that these experiments were conducted with the nanoparticles premixed into the sandpack. To better simulate the field condition, the nickel nanoparticle should be introduced into the reservoir in the form of nanofluid that is stable under reservoir conditions. However, due to its high surface energy, nanoparticles have a high tendency of agglomeration, making their suspension in a base fluid challenging ( $\mathrm{Li}$ et al. 2007). Therefore, to achieve a better recovery performance, it is of critical importance to ensure that the nanoparticle suspension is stable, and can carry the nanoparticles into deeper locations of the reservoir.

Much research has been devoted to exploring how to stabilize nano-suspensions (Russel et al. 1992; Wen and Ding 2005; Li et al. 2007; Ruan and Jacobi 2012; Kavitha et al. 2012; Devendiran and Amirtham 2016; Sun et al. 2017); these stabilization methods mainly include three types: (1) changing the $\mathrm{pH}$ value of nano-suspension; (2) using surfactants; and (3) using ultrasonic vibration. The London-van der Waals attractive force and the electrostatic repulsion between two charged particles are the two major forces affecting the stability of nanofluid (Williams et al. 2006). Certain surface treatment on the nanoparticles is a commonly applied technique to achieve a better stabilization effect of nanofluids (Williams et al. 2006). Surface charge of the particle surfaces can be created by adding acid or charged surfactants into the suspension. For example, $\mathrm{Li}$ et al. (2007) tested three surfactants: TX-10, CTAB and SDBS, in terms of their performance in stabilizing copper nanoparticle suspensions and studied the influences of surfactant type, surfactant concentration and $\mathrm{pH}$. Hwang et al. (2008) tested the use of SDS and oleic acid to stabilize nanofluids, finding that surfactants helped to create stable nanofluids by increasing the magnitude of the zeta potential. Xue and Sethi (2012) achieved the stabilization of a highly concentrated iron nanofluid using a mixture of guar gum and xanthan gum polymer. Kim et al. (2015) introduced a polymeric surfactant Hypermer KD-2 to prevent aggregation of nickel nanoparticles before their synthesis. Inspired by the above-mentioned research, cationic surfactant CTAB, anionic surfactant SDS and polymeric surfactant Hypermer KD-2 were introduced into nickel nanofluid separately or in a form of mixture together with xanthan gum polymer to stabilize the nickel nanofluid.

Previous research has been much devoted to looking at how much incremental oil recovery can be achieved by injecting nanoparticle suspensions (Muraza and Galadima 2015; Cheraghian and Hendraningrat 2016). But few have touched on how the nanofluid actually flows in porous media in a microscopic point of view. When nanofluid is being injected into the porous media, a deeper transportation and a better attachment of particle to oil/water interface and sand grains are both important. The transportation of nanoparticle flow in porous and fractured media has been studied by Alaskar et al. (2012). They demonstrated that the particle size, size distribution, particle shape and surface charge of the particles are influential parameters governing the transport of nanoparticles through porous media. It was concluded that the particles having opposite surface charge with the porous media tended to become trapped due to the affinity to the porous matrix, and surface modification with surfactant could improve its transport in the pore spaces. However, according to the investigation by Hamedi-Shokrlu and Babadagli (2014), in order to successfully let the nickel nanoparticles migrate to oil-water interfaces, the modification of the surface charge of oil phase by surfactant (having surface charge opposite to that of the nanofluid) is required. In other words, the surface charge of the oil phase must be opposite to the charge of the nickel nanoparticles so that a better attachment of nickel nanoparticles can be achieved. However, in their study, a very low nickel nanoparticle concentration $(0.050 \mathrm{wt} \%)$ is employed; in our study, the concentration of nickel nanoparticles is as higher as $1.000 \mathrm{wt} \%$ and $2.000 \mathrm{wt} \%$. Thus, to explore how the nickel nanoparticle would travel in porous media with such a high concentration, dynamic micromodel experiments were also carried out in this study.

To conclude, three surfactants (including CTAB, SDS and Hypermer KD-2) along with xanthan gum polymer were tested in this study to determine the polymer/surfactant recipes yielding the most stable nickel nanoparticle suspensions. In addition, micromodel tests were conducted to investigate the effect of nickel nanoparticle concentration and surface charge on the transport of nickel nanoparticles in porous media.

\section{Experimental section}

\subsection{Materials}

The diameter of the nickel nanoparticles (Sigma-Aldrich, Canada) used in this study was in the range of $40-70 \mathrm{~nm}$. Silica sand with the US mesh size of 40-70 was mixed with the mineral oil to make the micromodel. The mineral oil had a viscosity of $15,000 \mathrm{cP}$ at $25^{\circ} \mathrm{C}$. Three surfactants were considered in this study, i.e., anionic surfactant sodium dodecyl sulfate ( $\mathrm{SDS}, \mathrm{NaC}_{12} \mathrm{H}_{25} \mathrm{SO}_{4}$ ), cationic surfactant cetyltrimethylammonium bromide $\left(\mathrm{CTAB}, \mathrm{C}_{19} \mathrm{H}_{42} \mathrm{BrN}\right)$ 


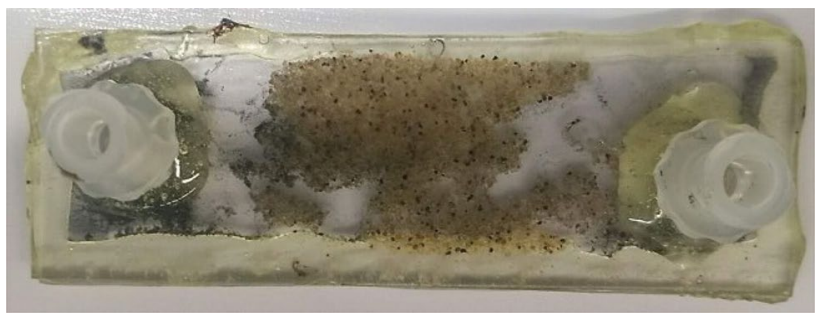

Fig. 1 Digital image of the micromodel $(7.5 \mathrm{~cm} \times 2.5 \mathrm{~cm})$ used in this study. This image was captured after the flow experiment was terminated

and polyoxyalkalene amine derivative (Hypermer KD-2), which is a polymeric surfactant. These three surfactants represent three major types of surfactants. The anionic polymer xanthan gum $\left(\mathrm{C}_{35} \mathrm{H}_{49} \mathrm{O}_{29}\right)$ was also tested in terms of its performance in stabilizing the nickel nanoparticle suspension because surfactant alone is found to be incapable of stabilizing high-concentration nanofluids.

\subsection{Experimental procedures}

This section describes the procedures for conducting the static stability test on the nickel nanoparticle suspensions and the procedures for conducting the dynamic micromodel flow test. Figure 1 shows the digital image of the micromodel $(7.5 \mathrm{~cm} \times 2.5 \mathrm{~cm})$ used in this study. This image was captured after the flow experiment was terminated.

In the beginning of the stability test, the nickel nanoparticles were added to the deionized water, resulting in nickel nanoparticle suspensions with weight concentrations of $1.000 \mathrm{wt} \%$ or $2.000 \mathrm{wt} \%$. Then, ultrasonication with a power of $200 \mathrm{~W}$ was applied to the suspension for $40 \mathrm{~min}$ to disperse nickel nanoparticles (Hamedi-Shokrlu and Babadagli 2014). Next, the surfactant or the mixture of surfactant and xanthan gum polymer were added to the nickel nanoparticle suspension, followed by a 40-min stirring of the suspension. Afterward, visual tests were then conducted to observe the possible sedimentation of the nickel nanoparticles in the suspension. The zeta potential of the most stable suspension solution is also measured. The detailed experimental scenarios are shown in Table 1. Based on the static stability tests, the polymer/surfactant recipes yielding the most stable nanoparticle suspensions were then determined.

The dynamic micromodel flow tests were conducted after the stability test. Since crude oil is not transparent, it is hard to visually observe the flow of nickel nanoparticle suspension even by trying a few types of fluorescent. Under this circumstance, the authors decided to use mineral oil, which enables the visual monitoring of the injection process. Silica sands were first mixed with the mineral oil dyed with fluorescent. Then, the silica sands mixed with mineral oil
Table 1 Experimental schemes used in the static stability tests conducted on the nanoparticle suspensions

\begin{tabular}{lllll}
\hline $\begin{array}{l}\text { Exp. \# } \\
\begin{array}{l}\text { Nickel con- } \\
\text { centration, } \\
\text { wt } \%\end{array}\end{array}$ & $\begin{array}{l}\text { Surfactant } \\
\text { type }\end{array}$ & $\begin{array}{l}\text { Surfactant } \\
\text { concentra- } \\
\text { tion, wt\% }\end{array}$ & $\begin{array}{l}\text { Polymer } \\
\text { concentration, } \\
\text { wt\% }\end{array}$ \\
\hline 1 & 1 & None & 0 & 0 \\
2 & 1 & CTAB & 1.00 & 0 \\
3 & 1 & CTAB & 1.00 & 0.030 \\
4 & 1 & SDS & 0.35 & 0 \\
5 & 1 & SDS & 0.50 & 0 \\
6 & 1 & SDS & 0.50 & 0.030 \\
7 & 1 & SDS & 0.50 & 0.045 \\
8 & 1 & SDS & 0.35 & 0.045 \\
9 & 1 & KD-2 & 0.35 & 0 \\
10 & 1 & KD-2 & 1.00 & 0 \\
11 & 1 & KD-2 & 2.00 & 0 \\
12 & 1 & KD-2 & 0.35 & 0.045 \\
13 & 2 & SDS & 0.50 & 0.060 \\
\hline
\end{tabular}

were spread on one glass sheet and subsequently covered by another sheet to make the micromodel. A syringe pump was used to inject the nickel nanoparticle suspension into the micromodel, and the camera attached to the microscope was employed to monitor the migration of the nickel nanoparticles in the micromodel. Table 2 shows the experimental schemes employed in the dynamic flow tests.

\section{Results and discussion}

\subsection{Static stability tests of nickel nanoparticle suspensions}

Figure 2 shows the images of water mixed with the nickel nanoparticles before and after ultrasonication. When mixed with deionized water, the nickel nanoparticles can aggregate due to the strong van der Waals interactions, as depicted in Fig. 2a. However, as observed in Fig. 2b, when being treated by ultrasonication, the agglomeration could be disturbed and the nickel nanoparticles could disperse in deionized water homogeneously, forming nickel nanoparticle suspension. However, when the ultrasonication was terminated, these nickel nanoparticles will aggregate and precipitate again. Figure 3 shows the images captured in Exp. \#1 at different times after the ultrasonication was terminated. As shown in Fig. 3, a clear interface appeared 2 min right after the sample preparation; after $8 \mathrm{~min}$, the majority of the nickel nanoparticles precipitated again.

Previously, two approaches were used to enhance the stability of the nanoparticle suspension: (1) to use surfactant to enhance the electric repulsion force among 
Table 2 Experimental schemes used in the dynamic flow tests

\begin{tabular}{llllll}
\hline Exp. \# & $\begin{array}{l}\text { Nickel concentra- } \\
\text { tion, wt } \%\end{array}$ & Surfactant type & $\begin{array}{l}\text { Surfactant concen- } \\
\text { tration, wt } \%\end{array}$ & $\begin{array}{l}\text { Polymer concentra- } \\
\text { tion, wt } \%\end{array}$ & Comment \\
\hline 2.1 & 2 & SDS & 0.500 & 0.060 & Directly inject the nanoparticle suspension \\
2.2 & 1 & SDS & 0.350 & 0.045 & Directly inject the nanoparticle suspension \\
2.3 & 1 & KD-2 & 0.350 & 0.045 & Directly inject the nanoparticle suspension \\
2.4 & 1 & CTAB & 1.000 & 0.045 & $\begin{array}{c}\text { Inject CTAB first, followed by injection of } \\
\text { nickel nanoparticle suspension }\end{array}$ \\
\hline
\end{tabular}
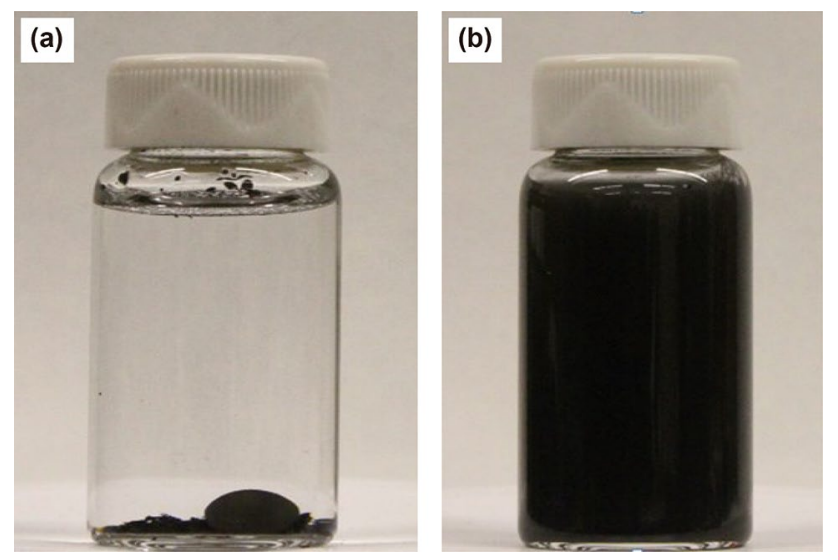

Fig. 2 Nickel nanoparticle in deionized water: a before ultrasonication; $\mathbf{b}$ after ultrasonication

nickel nanoparticles and (2) to increase the viscosity of the base fluid to decrease the settling velocity of the particles (Hamedi-Shokrlu and Babadagli 2014). In Exp. \#2, cationic surfactant CTAB was added to enhance the stability of the nickel nanoparticle suspension. Figure 4a shows the images of the nickel nanoparticle suspension (prepared with 1.000 wt $\%$ CTAB surfactant) captured at different times after ultrasonication. As observed from Fig. 4a, the nickel suspension prepared with $1.000 \mathrm{wt} \%$ CTAB exhibited a poor stability. Moreover, the stability test on suspensions prepared with other CTAB concentrations was conducted, and the same phenomenon was observed, as shown in Fig. 4a. Based on the observation from $\mathrm{Li}$ et al. (2007), by introducing the CTAB, the nanoparticles tend to form agglomerated structures when $\mathrm{pH}$ is lower than 7 , while a good dispersion can be resulted when $\mathrm{pH}$ is in the range of 9-10. Therefore, the neutral $\mathrm{pH}$ level $(\mathrm{pH}=7)$ of the tested suspension in this study may be the reason leading to the instability of the nickel nanoparticle suspensions. Subsequently, the stability of the suspension prepared with xanthan gum polymer and CTAB surfactant was tested in Exp. \#3. Figure 4b shows the images of the nickel nanoparticle suspension (prepared with $1.000 \mathrm{wt} \%$ CTAB and $0.030 \mathrm{wt} \%$ xanthan gum polymer) captured at different times after ultrasonication. As expected, a rapid agglomeration of nickel nanoparticles was observed in this test due to the opposite surface charge between CTAB and xanthan gum polymer.

Figure $4 \mathrm{c}$ shows the images of the nickel nanoparticle suspension (prepared with $0.350 \mathrm{wt} \%$ SDS) captured at different times after ultrasonication. Compared with the suspension prepared with CTAB, the nickel nanoparticle suspension prepared with SDS was more stable and no obvious precipitation was observed after $8 \mathrm{~min}$. Thereof, SDS can

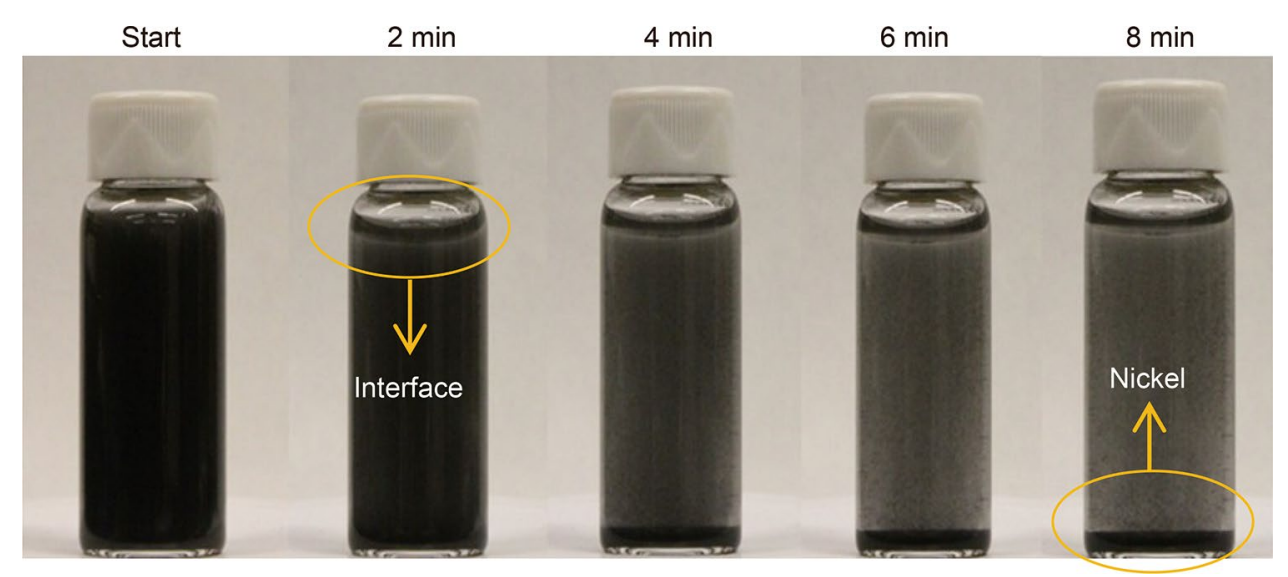

Fig. 3 Images of the nickel nanoparticle suspension (prepared without surfactant or polymer) captured at different times after ultrasonication 
be used to enhance the stability of nickel nanoparticle suspension. However, after $20 \mathrm{~min}$, it started to aggregate; the aggregation became more serious after $40 \mathrm{~min}$.

Xanthan gum polymer was then introduced into the nickel nanoparticle suspension with $0.350 \mathrm{wt} \%$ SDS to improve the stability of the suspension. The xanthan gum polymer dissolved in water increased the stability of the nickel nanoparticle suspension by increasing its viscosity. However, the chance of formation clogging increases as the viscosity of the fluid increases (Hamedi-Shokrlu and Babadagli 2014). Therefore, when preparing the nickel nanoparticle suspension, the viscosity of the suspension is the key parameter to consider. To obtain a proper suspension viscosity, in Exp. \#6, initially, the suspension with $0.030 \mathrm{wt} \%$ of xanthan gum polymer was prepared, whose viscosity was measured to be $1.7 \mathrm{cP}$ at $25^{\circ} \mathrm{C}$. However, as observed from the photographs, the suspension aggregated within $40 \mathrm{~min}$ due to the high nickel concentration. Thus, the polymer concentration was increased to $0.045 \mathrm{wt} \%$ with different concentrations of SDS added. Figure $4 \mathrm{~d}$ shows the images of the nickel nanoparticle suspension prepared with $0.045 \mathrm{wt} \%$ xanthan gum polymer and $0.350 \mathrm{wt} \%$ SDS. As shown in Fig. 4d, no aggregation was observed in the suspension even after $60 \mathrm{~min}$; the zeta potential of this suspension was measured to be $-52 \mathrm{mV}$, confirming a good stability. The reason of using surfactant together with polymer to prepare the suspension is not only because the surfactant can increase the surface charge of the particles, but also can lower down the interfacial tension between oil and water.

Another surfactant is Hypermer KD-2, a liquefied polymeric surfactant with a viscosity of $135 \mathrm{cP}$ at $25^{\circ} \mathrm{C}$. Based on the observation from Kim et al. (2015), Hypermer KD-2 can stabilize nickel nanoparticle suspension for over a week. However, in Exps. \#9-11, even when the concentration of Hypermer KD-2 was increased from 0.350 to $2.000 \mathrm{wt} \%$, the stabilization of the suspension experienced little change; it was probably caused by the high concentration of nickel nanoparticles. In Exp. \#12, $0.045 \mathrm{wt} \%$ of xanthan gum polymer, together with $0.350 \mathrm{wt} \%$ of Hypermer KD-2 surfactant, was added to the suspension. Figure 4e shows the images captured during Exp. \#12 after ultrasonication. As shown in Fig. 4e, there was no aggregation observed in the suspension even after $60 \mathrm{~min}$; thereof, this suspension exhibited a good stability. The zeta potential of this suspension was measured to be $-55 \mathrm{mV}$, validating a good stability of this nickel nanoparticle suspension.

To summarize, the surfactant alone, i.e., CTAB, SDS or Hypermer KD-2, could not well enhance the stability of the nickel nanoparticle suspension. However, when being used together with xanthan gum polymer, it could increase the stability of the suspension. It is found that $(0.045 \mathrm{wt} \%$ xanthan gum polymer and $0.350 \mathrm{wt} \%$ of surfactant SDS) or $(0.045 \mathrm{wt} \%$ of xanthan gum polymer and $0.350 \mathrm{wt} \%$
Hypermer KD-2) could make the suspension stable as long as $60 \mathrm{~min}$. However, if the concentration of nickel nanoparticle increases to $2.000 \mathrm{wt} \%$, a higher concentration of surfactant and polymer (i.e., $0.060 \mathrm{wt} \%$ xanthan gum polymer and $0.500 \mathrm{wt} \% \mathrm{SDS}$ ) was required to obtain a stabilized suspension.

\subsection{Dynamic micromodel flow tests}

After determining the polymer/surfactant recipes giving the most stable nickel nanoparticle suspensions, dynamic micromodel flow tests were conducted using these suspensions to investigate the migration of nanoparticles in the micromodel. An initial injection rate of $0.05 \mathrm{~mL} / \mathrm{min}$ was first applied to study the transport of the injected particles in porous media. Exp. \#2.1 used the suspension prepared with $2.000 \mathrm{wt} \%$ nickel nanoparticles, $0.500 \mathrm{wt} \%$ SDS and $0.060 \mathrm{wt} \%$ xanthan gum polymer. Figure 5 shows the images at the injection port before and after the nanofluid injection. In Fig. 5a, the channels at the injection port before the suspension injection could be clearly observed. As depicted in Fig. 5b, after injecting the suspension $(2.000 \mathrm{wt} \%$ nickel nanoparticles, $0.500 \mathrm{wt} \%$ SDS and $0.060 \mathrm{wt} \%$ xanthan gum polymer) into the micromodel, both the small and large pores were blocked. It was possibly caused by the high concentration of nickel nanoparticles in the suspension. The nickel nanoparticles with such a high concentration may get easily adsorbed on the surface of the silica sands due to the strong surface/particle interactions.

The injecting of the suspension is stopped right before the breakthrough of the suspension. In field applications, companies can only afford to inject slugs of nanoparticle suspension into the reservoir due to the fact that nanoparticles are expensive. Alternative injection of the nanoparticle suspension and steam should be pursued. To simulate the steam (which condenses into water under reservoir condition) injection after the injection of the nanoparticle suspension, waterflooding was conducted to investigate the effect of injected water on the distribution of nanoparticles in the pore configurations. Figure 6 shows the distributions of the nickel nanoparticles in the pore configurations before and after the waterflooding. It can be seen that the distribution of the nanoparticles was almost unchanged when the injection rate was low (i.e., $0.05 \mathrm{~mL} /$ $\min )$. As shown in Fig. 6b, the distribution of these nanoparticles after waterflooding was identical to that before the waterflooding. Consequently, the sensitivity of the distribution to the injection rate was further investigated by increasing the injection rate of water. After increasing the injection rate to $0.5 \mathrm{~mL} / \mathrm{min}$, the distribution of the nanoparticles remains unchanged in the micromodel. This may be attributed to the following two reasons: (1) The injection rate was still low; as a result, the viscous force was 
(a)

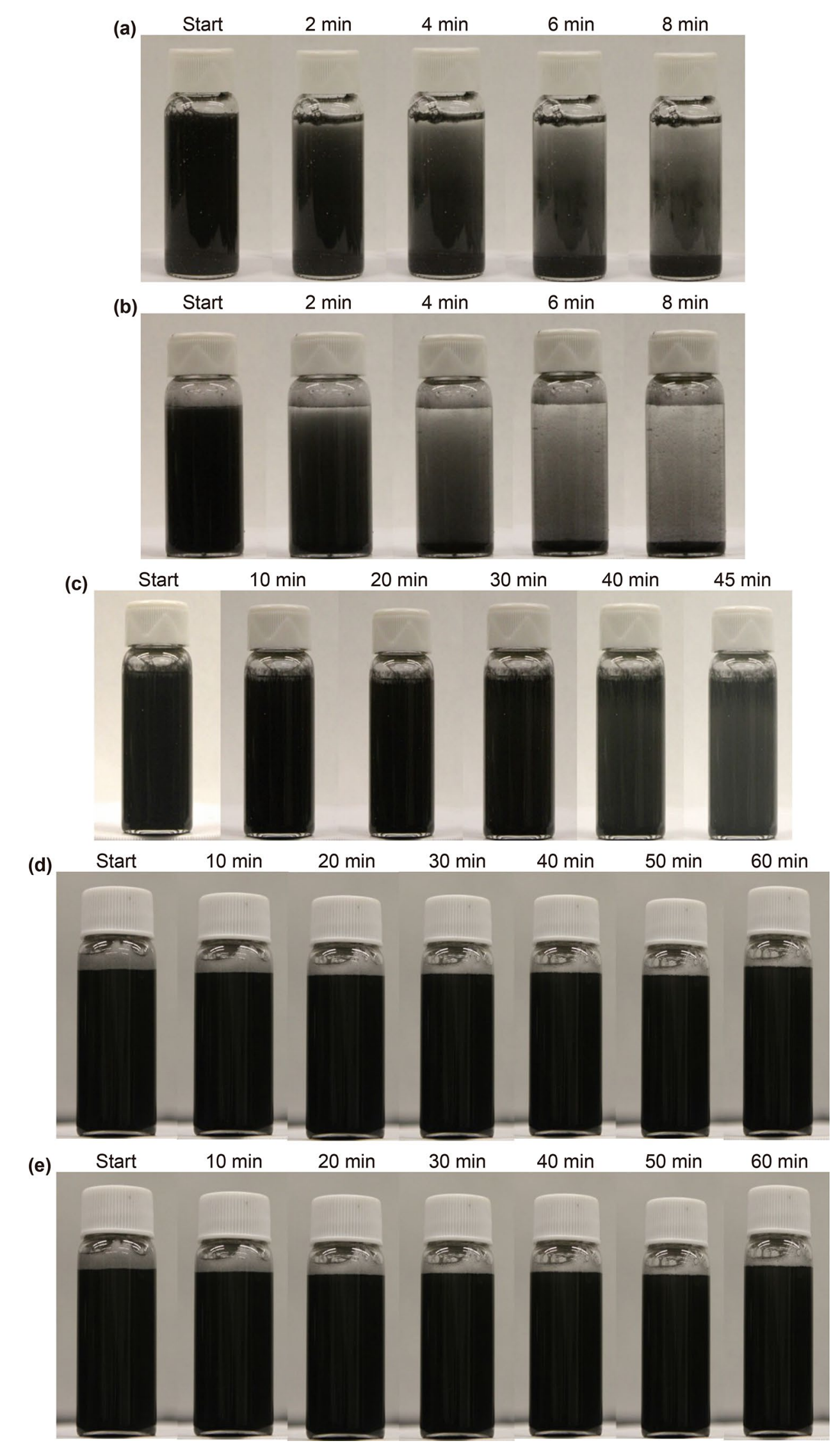

$4 \mathrm{~min}$

$6 \mathrm{~min}$


4Fig. 4 Images of the nickel nanoparticle suspension (prepared with different surfactants or different surfactants along with xanthan gum polymer) captured at different times after ultrasonication: a prepared with $1.000 \mathrm{wt} \%$ CTAB surfactant; b prepared with $1.000 \mathrm{wt} \%$ CTAB and $0.030 \mathrm{wt} \%$ xanthan gum polymer; c prepared with $0.350 \mathrm{wt} \%$ SDS; d prepared with $0.350 \mathrm{wt} \%$ SDS and $0.045 \mathrm{wt} \%$ xanthan gum polymer; e prepared with 0.350 wt $\%$ Hypermer KD-2 and 0.045 wt $\%$ xanthan gum polymer)

not able to remove the precipitated nanoparticles. (2) The injected water might flow through the pores unblocked by the nickel nanoparticles. Figure 7 presents the distribution of the particles at other locations in the micromodel. As depicted in Fig. 7, the nanoparticles were mostly present in the injection end, while few nanoparticles were present in other areas. The visual observations indicate that only a small number of nickel nanoparticles tended to be attached to the sand surface. Most of the particles had been transported into the production end.
In Exp. \#2.2, the nickel nanofluid comprising of $1.000 \mathrm{wt} \%$ nickel, $0.350 \mathrm{wt} \%$ SDS and $0.045 \mathrm{wt} \%$ xanthan gum polymer was injected into the porous media. Similarly, most of the particles tended to flow toward the production end during the injection period. Moreover, as observed, the distribution and attachment of the nanoparticles were also not influenced by waterflooding. Figure 8 shows the images taken after waterflooding. As indicated by Fig. $8 \mathrm{a}-\mathrm{c}$, less agglomeration was observed near the injection port for the suspension with lower nickel concentration. Figure 9 presents the distribution of the nickel nanoparticles in the micromodel after waterflooding in Exp. \#2.3 (1.000 wt\% nickel suspension, $0.350 \mathrm{wt} \%$ Hypermer KD-2 and 0.045 wt\% xanthan gum polymer). It can be seen from Fig. 9 that the nickel nanoparticles, either near the injection port or around the production point, appeared to be uniformly attached on the surface of sand grains.
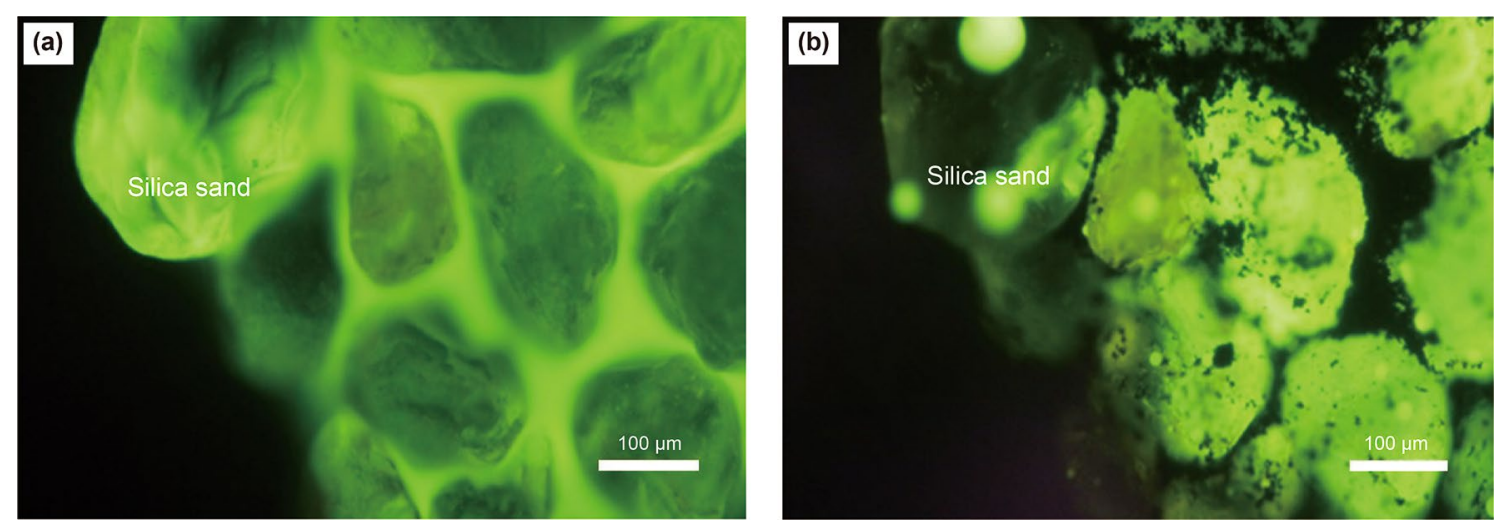

Fig. 5 The images near the injection port in the micromodel $\mathbf{a}$ before and $\mathbf{b}$ after the injection of 2.000 wt $\%$ nickel nanoparticle suspension prepared with $0.500 \mathrm{wt} \% \mathrm{SDS}$ and $0.060 \mathrm{wt} \%$ xanthan gum polymer
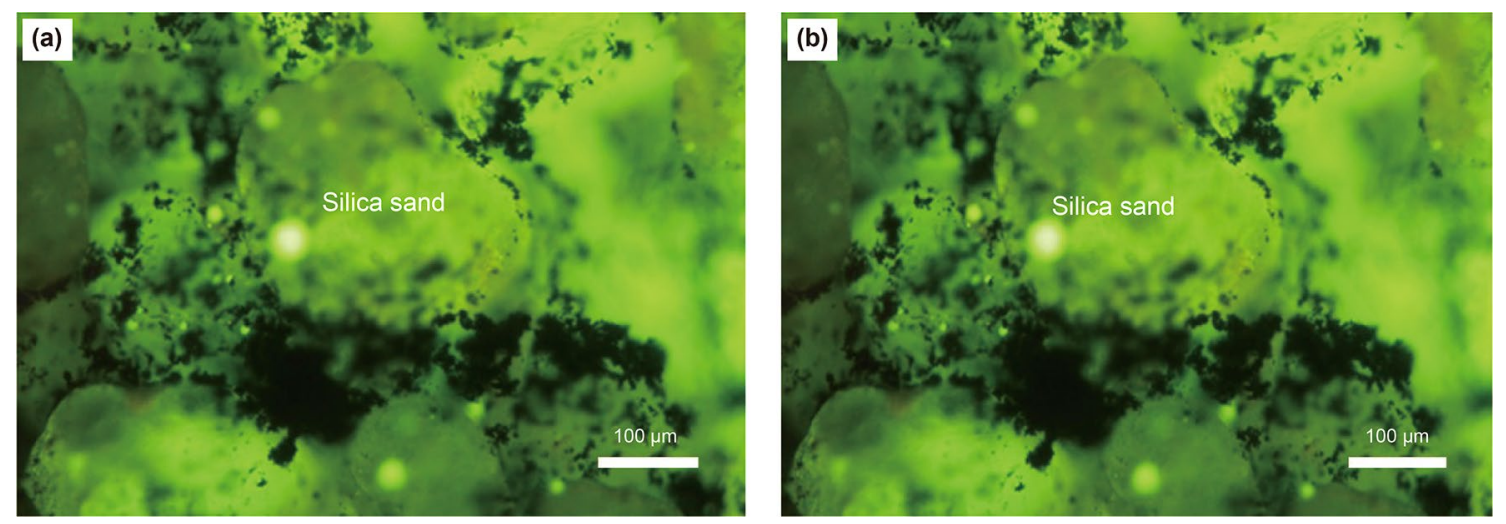

Fig. 6 The images taken at the same location in Exp. \#2.1 $\mathbf{a}$ before and $\mathbf{b}$ after waterflooding 

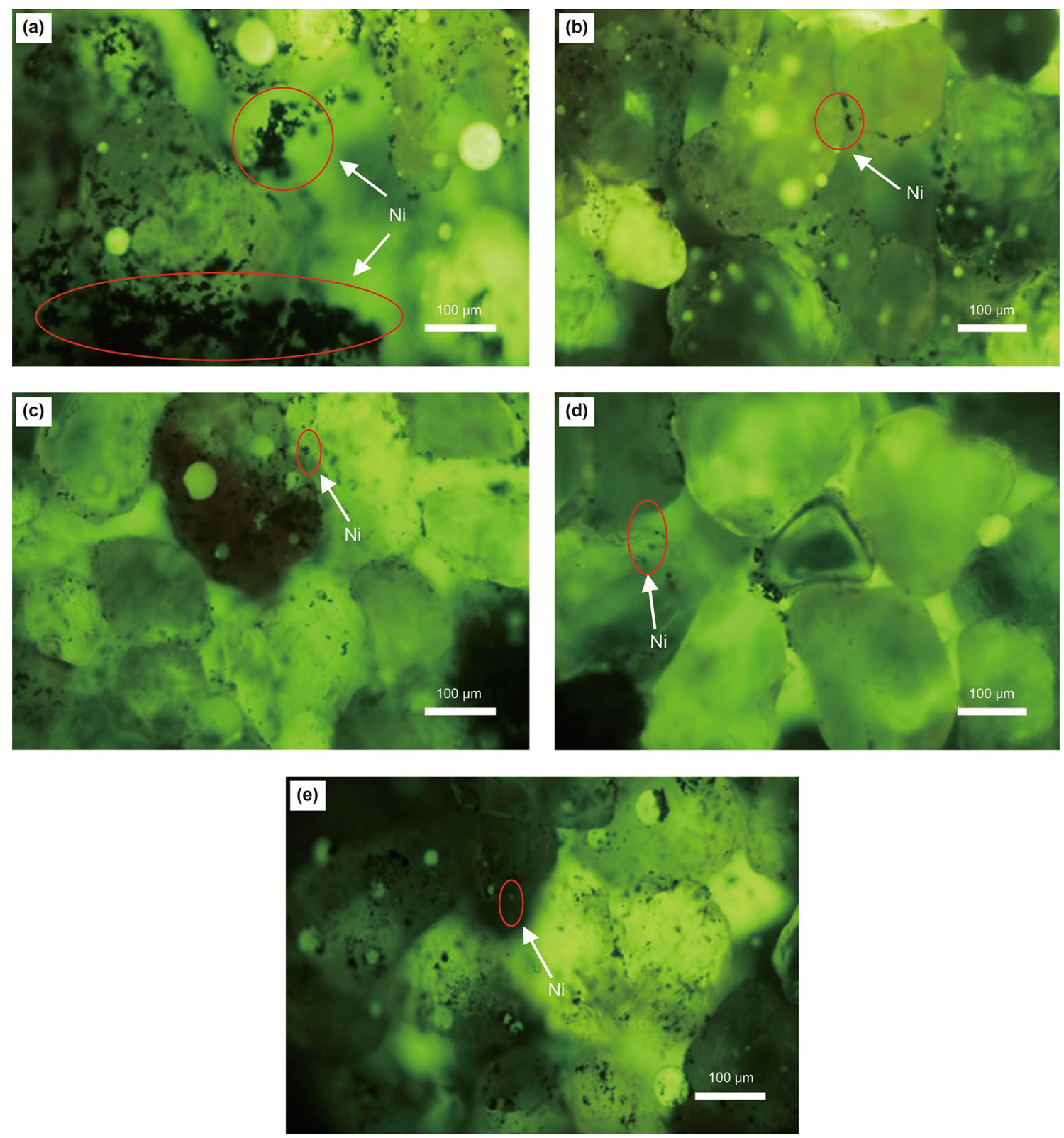

Fig. 7 Images taken at different locations of the micromodel in Exp. \#2.1 after waterflooding: a around injection port; $\mathbf{b}$ in the middle; $\mathbf{c}$ around the production end; $\mathbf{d}$ the upper part; and $\mathbf{e}$ the lower part

Hamedi-Shokrlu and Babadagli (2014) conducted micromodel experiments by injecting CTAB solution into a micromodel first and then followed by injecting the nickel nanoparticle suspension with xanthan gum polymer. They proposed that one slug of CTAB surfactant should be injected to alter the surface charge of the silica sands, enabling the nickel nanoparticle to be more easily moved to the sand surface. As observed from Exps. \#2.2 and \#2.3, when nickel nanoparticles made contact with the silica sands, the negatively charged nickel nanoparticles could get adsorbed on the sand surface. In Exp. \#2.4, CTAB was injected first to alter the surface charges of the sand grains, followed by injection of the nickel nanoparticle suspension. Figure 10 shows the images taken at different locations of the micromodel in Exp. \#2.4 after waterflooding. It can be seen from Fig. 10 that after the surface charge of sands was altered from being negative to being positive, large clusters of nickel nanoparticle could form and become trapped on the sand surface. 

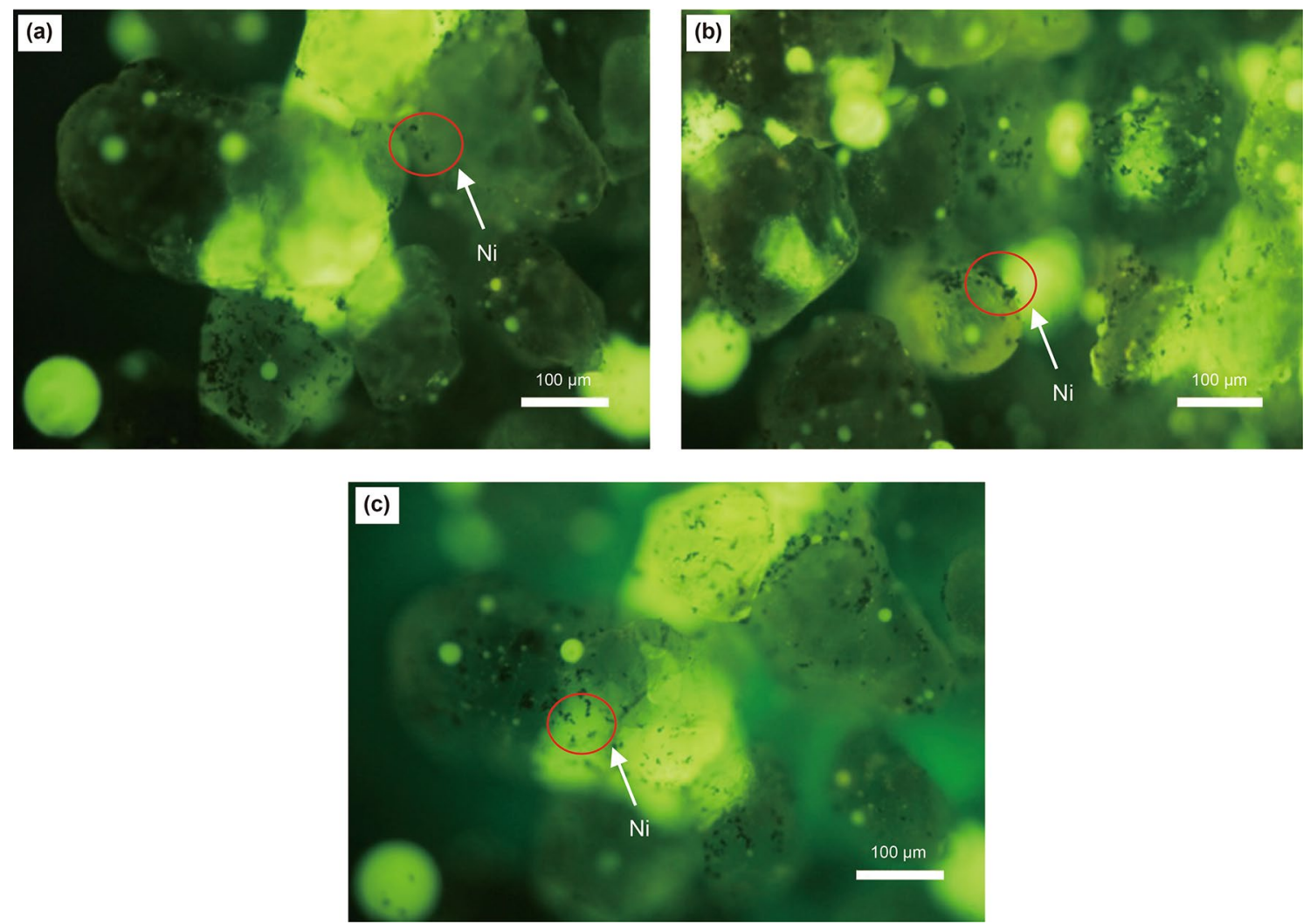

Fig. 8 Images taken at different locations of the micromodel in Exp. \#2.2 after waterflooding (1.000 wt\% nickel nanoparticle suspension with SDS and xanthan gum polymer): $\mathbf{a}$ around injection port; $\mathbf{b}$ in the middle part; $\mathbf{c}$ near the production end
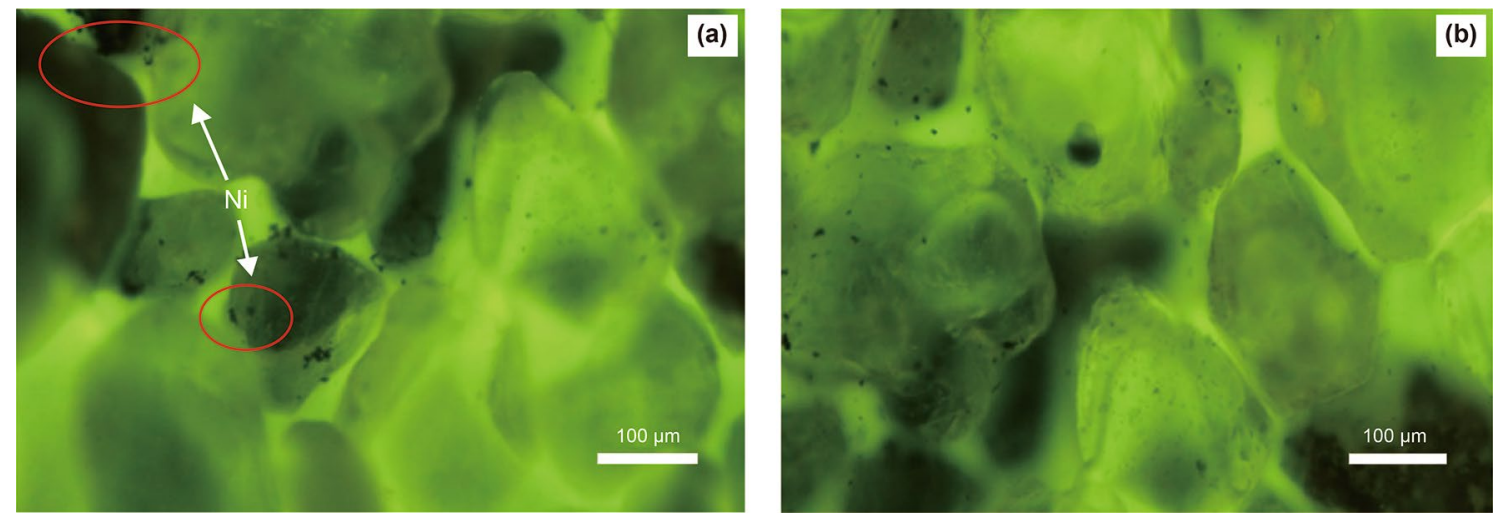

Fig. 9 Images taken at different locations of the micromodel in Exp. \#2.3 after waterflooding (1.000 wt\% nickel nanoparticle suspension with Hypermer KD-2 and xanthan gum polymer): $\mathbf{a}$ around the injection port; $\mathbf{b}$ around the production port

To summarize, as observed from the micromodel experiments, the nanofluid with a lower nickel concentration could help to increase the injectivity of the nanoparticles. If the injected nanofluid has a surface charge opposite to that of the porous media, clusters could be formed more easily on the sand surface, hampering the migration of the nanoparticles to the deeper reservoir. The recipes determined which are considered to well enhance the stability of the suspension are: $(1.000 \mathrm{wt} \% \mathrm{Ni}+0.350 \mathrm{wt} \% \mathrm{SDS}+0.045$ wt $\%$ xanthan gum polymer $),(1.000 \mathrm{wt} \% \mathrm{Ni}+0.350 \mathrm{wt} \%$ Hypermer KD-2 $+0.045 \mathrm{wt} \%$ xanthan gum polymer) and $(2.000 \mathrm{wt} \% \mathrm{Ni}+0.500 \mathrm{wt} \% \mathrm{SDS}+0.060 \mathrm{wt} \%$ xanthan gum polymer). In the field application, a suitable concentration of nickel nanoparticles should be selected, and the charges of both the injected suspension and the pore surface should be considered in order to achieve a desirable placement of 

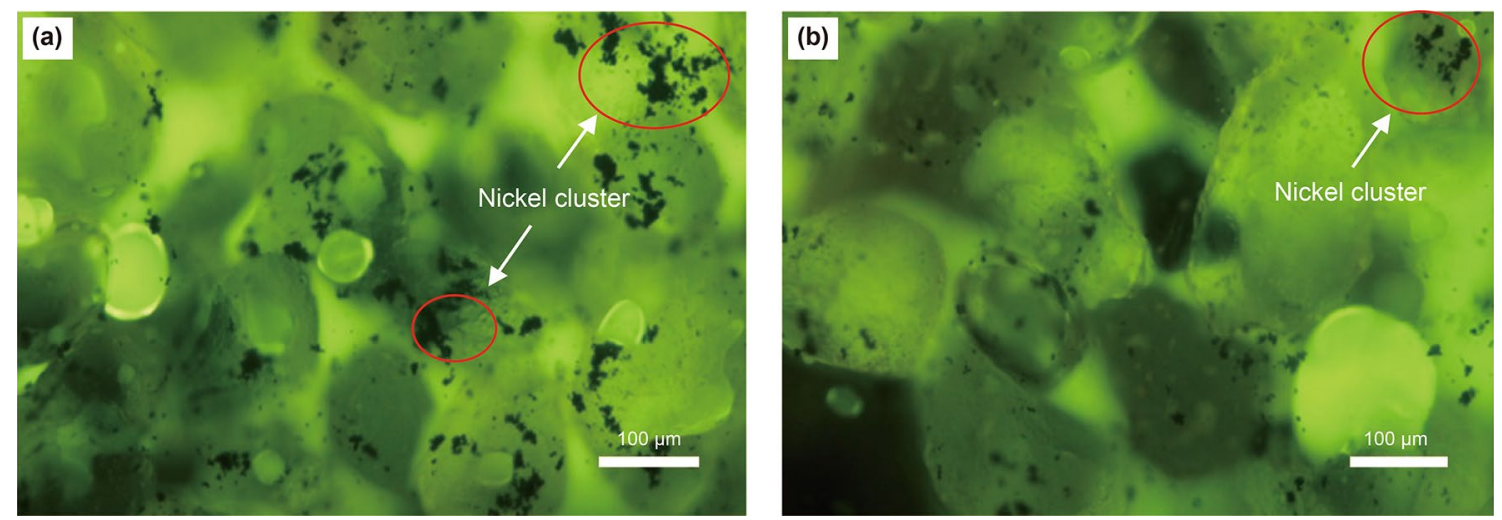

Fig. 10 Images taken at different locations of the micromodel in Exp. \#2.4 after waterflooding (CTAB solution followed by 1.000 wt\% nickel nanoparticle suspension with xanthan gum polymer): a injection port; $\mathbf{b}$ production port

the nanoparticles, i.e., the nanoparticles should be placed deeper into the reservoir and becoming more spreading over the grain surface without forming clusters.

\section{Conclusions}

In this study, the stability tests on nickel nanoparticle suspensions that were prepared with polymer and surfactant additives were conducted, followed by the dynamic flow test to investigate the migration of such nanoparticles in the micromodel. The detailed conclusions can be drawn as follows:

(1) The surfactant (i.e., CTAB, SDS and Hypermer KD-2), if individually used, cannot well stabilize the nickel nanoparticle suspension.

(2) After introducing certain amount of xanthan gum polymer into the system, the stability of such nickel nanoparticle suspension was improved. When being used in conjunction with surfactant, a higher polymer concentration loading is required to stabilize the nanosuspension with a higher nanoparticle concentration.

(3) When the suspension comprising of high-concentration nickel nanoparticle is injected into the micromodel, the nickel nanoparticles tend to agglomerate severely and then block the channels near the injection port.

(4) A smaller number of the nickel nanoparticles tend to be adsorbed onto the surface of the sand grains when nanoparticles have the same surface charge with the silica sand.

(5) If the silica sands were first treated with CTAB surfactant, alternating its surface charge from negative to positive, larger clusters will form and become trapped in porous media.

(6) In the field application, a suitable concentration of nickel nanoparticles should be carefully selected in order to achieve a desirable placement of the nanoparticles. This is a challenging job considering that there are many influencing parameters involved in this process.

Acknowledgements This research was conducted under T. Babadagli's NSERC Industrial Research Chair in Unconventional Oil Recovery (industrial partners are Petroleum Development Oman, Total E\&P Recherche Développement, SIGNa Oilfield Canada, CNRL, SUNCOR, Touchstone Exploration, Sherritt Oil, PEMEX, Husky Energy, Saudi Aramco, Devon and APEX Eng.). We also thank the financial support provided by NSERC Discovery Grants to T. Babadagli (No: RES0011227) and H. Li (No. NSERC RGPIN 05394).

Open Access This article is licensed under a Creative Commons Attribution 4.0 International License, which permits use, sharing, adaptation, distribution and reproduction in any medium or format, as long as you give appropriate credit to the original author(s) and the source, provide a link to the Creative Commons licence, and indicate if changes were made. The images or other third party material in this article are included in the article's Creative Commons licence, unless indicated otherwise in a credit line to the material. If material is not included in the article's Creative Commons licence and your intended use is not permitted by statutory regulation or exceeds the permitted use, you will need to obtain permission directly from the copyright holder. To view a copy of this licence, visit http://creativecommons.org/licenses/by/4.0/.

\section{References}

Alaskar M, Ames M, Connor S, Liu C, Cui Y, Li K, Horne R. Nanoparticle and microparticle flow in porous and fractured mediaan experimental study. SPE J. 2012;17(04):1-160. https://doi. org/10.2118/146752-PA.

Cheraghian G, Hendraningrat L. A review on applications of nanotechnology in the enhanced oil recovery part B: effects of nanoparticles on flooding. Int Nano Lett. 2016;6(1):1-10. https://doi. org/10.1007/s40089-015-0170-7.

Clark PD, Clarke RA, Hyne JB. Studies on the effect of metal species on oil sands undergoing steam treatments. AOSTRA J. Res. 1990;6(1):53-64.

Devendiran DK, Amirtham VA. A review on preparation, characterization, properties and applications of nanofluids. Renew 
Sustain Energy Rev. 2016;60:21-40. https://doi.org/10.1016/j. rser.2016.01.055.

Hamedi-Shokrlu Y, Babadagli T. Stabilization of nanometal catalysts and their interaction with oleic phase in porous media during enhanced oil recovery. Ind Eng Chem Res. 2014;53(20):846475. https://doi.org/10.1021/ie4042033.

Hashemi R, Nassar NN, Pereira Almao P. Enhanced heavy oil recovery by in situ prepared ultradispersed multimetallic nanoparticles: a study of hot fluid flooding for Athabasca bitumen recovery. Energy Fuels. 2013;27(4):2194-201. https://doi. org/10.1021/ef3020537.

Hwang Y, Lee JK, Lee JK, Jeong YM, Cheong SI, Ahn YC, Kim SH. Production and dispersion stability of nanoparticles in nanofluids. Powder Technol. 2008;186(2):145-53. https://doi. org/10.1016/j.powtec.2007.11.020.

Kavitha T, Rajendran A, Durairajan A. Synthesis, characterization of $\mathrm{TiO}_{2}$ nano powder and water based nanofluids using two step method. Eur J Appl Eng Sci Res. 2012;1:235-40.

Kong X, Ohadi M. Applications of micro and nano technologies in the oil and gas industry-overview of the recent progress. In: SPE international petroleum exhibition and conference, Abu Dhabi, 1-4 Nov; 2010. https://doi.org/10.2118/138241-MS.

Kim CK, Lee GJ, Lee MK, Rhee CK. A study on dispersion stability of nickel nanoparticles synthesized by wire explosion in liquid media. Arch Metall Mater. 2015;60(2):1379-82.

Li X, Zhu D, Wang X. Evaluation on dispersion behavior of the aqueous copper nano-suspensions. J Colloid Interface Sci. 2007;310(2):456-63. https://doi.org/10.1016/j. jcis.2007.02.067.

Muraza O, Galadima A. Aquathermolysis of heavy oil: a review and perspective on catalyst development. Fuel. 2015;157:219-31. https://doi.org/10.1016/j.fuel.2015.04.065.
Ragab AMS, Hannora AE. An experimental investigation of silica nano particles for enhanced oil recovery applications. In: SPE North Africa technical conference and exhibition, Cairo, 14-16 Sept; 2015. https://doi.org/10.2118/175829-MS.

Ruan B, Jacobi AM. Ultrasonication effects on thermal and rheological properties of carbon nanotube suspensions. Nanoscale Res Lett. 2012;7:127. https://doi. org/10.1186/1556-276X-7-127.

Russel WB, Saville DA, Schowalter WR. Colloidal dispersions. J Chem Technol Biotechnol. 1992;54:201-2.

Sun X, Zhang Y, Chen G, Gai Z. Application of nanoparticles in enhanced oil recovery: a critical review of recent progress. Energies. 2017;10:345. https://doi.org/10.3390/en10030345.

Wei L, Zhu JH, Qi JH. Application of nano-nickel catalyst in the viscosity reduction of Liaohe extra-heavy oil by aqua-thermolysis. J Fuel Chem Technol. 2007;35(2):176-80. https://doi.org/10.1016/ S1872-5813(07)60016-4.

Wen D, Ding Y. Experimental investigation into the pool boiling heat transfer of aqueous based $\gamma$-alumina nanofluids. J Nanoparticle Res. 2005;7:265-74. https://doi.org/10.1007/s11051-005-3478-9.

Williams WC, Bang IC, Forrest E, Hu LW, Buongiorno J. Preparation and characterization of various nanofluids. In: NSTI nanotechnology conference and trade show, vol 2. 2006. p. 408-11.

Xue D, Sethi R. Viscoelastic gels of guar and xanthan gum mixtures provide long-term stabilization of iron micro-and nanoparticles. J Nanoparticle Res. 2012;14(11):1239. https://doi.org/10.1007/ s11051-012-1239-0.

Yi S, Babadagli T, Li HA. Use of nickel nanoparticles for promoting aquathermolysis reaction during cyclic steam stimulation. SPE J. 2017;23(1):145-56. https://doi.org/10.2118/186102-PA. 